Article

\title{
Genetic Characterization of Chikungunya Virus in Field-Caught Aedes aegypti Mosquitoes Collected during the Recent Outbreaks in 2019, Thailand
}

\author{
Proawpilart Intayot ${ }^{1}$, Atchara Phumee ${ }^{2,3}{ }^{-}$, Rungfar Boonserm ${ }^{3}$, Sriwatapron Sor-suwan ${ }^{3}$, \\ Rome Buathong ${ }^{4}$, Supaporn Wacharapluesadee ${ }^{2}$, Narisa Brownell ${ }^{3}$, Yong Poovorawan ${ }^{5}$ and \\ Padet Siriyasatien $3, *$ (D) \\ 1 Medical Science Program, Faculty of Medicine, Chulalongkorn University, Bangkok 10330, Thailand \\ 2 Thai Red Cross Emerging Infectious Diseases-Health Science Centre, World Health Organization \\ Collaborating Centre for Research and Training on Viral Zoonoses, Chulalongkorn Hospital, \\ Bangkok 10330, Thailand \\ 3 Vector Biology and Vector Borne Disease Research Unit, Department of Parasitology, Faculty of Medicine, \\ Chulalongkorn University, Bangkok 10330, Thailand \\ 4 Bureau of Epidemiology, Department of Disease Control, Ministry of Public Health, \\ Nonthaburi 11000, Thailand \\ 5 Center of Excellence in Clinical Virology, Faculty of Medicine, Chulalongkorn University, \\ Bangkok 10330, Thailand \\ * Correspondence: padet.s@chula.ac.th; Tel.: +66-2256-4387
}

Received: 30 June 2019; Accepted: 1 August 2019; Published: 2 August 2019

check for updates

\begin{abstract}
Chikungunya virus (CHIKV) is a mosquito-borne virus belonging to the genus Alphavirus. The virus is transmitted to humans by the bite of infected female Aedes mosquitoes, primarily Aedes aegypti. CHIKV infection is spreading worldwide, and it periodically sparks new outbreaks. There are no specific drugs or effective vaccines against CHIKV. The interruption of pathogen transmission by mosquito control provides the only effective approach to the control of CHIKV infection. Many studies have shown that CHIKV can be transmitted among the Ae. aegypti through vertical transmission. The previous chikungunya fever outbreaks in Thailand during 2008-2009 were caused by CHIKV, the East/Central/South African (ECSA) genotype. Recently, there have been 3794 chikungunya cases in 27 provinces reported by the Bureau of Epidemiology of Health Ministry, Thailand during 1 January-16 June 2019; however, the cause of the re-emergence of CHIKV outbreaks is uncertain. Therefore, the aims of this study were to detect and analyze the genetic diversity of CHIKV infection in field-caught mosquitoes. Both female and male Ae. aegypti were collected from endemic areas of Thailand, and CHIKV detection was done by using E1-nested RT-PCR and sequencing analysis. A total of $1646 \mathrm{Ae}$. aegypti samples (900 females and 746 males) were tested. CHIKV was detected in $54(3.28 \%)$ and 14 samples $(0.85 \%)$ in female and male mosquitoes, respectively. Seventeen samples of female Ae. aegypti collected from the Ubon Ratchathani, Chiang Rai, Chiang Mai, Nakhon Sawan, and Songkhla provinces found mutation at E1: A226V. Interestingly, E1: K211E mutation was observed in 50 samples collected from Nong Khai, Bangkok, Prachuap Khiri Khan, and Krabi. In addition, the phylogenetic tree indicated that CHIKV in Ae. aegypti samples were from the Indian Ocean Clade and East/South African Clade. Both clades belong to the ECSA genotype. The information obtained from this study could be used for prediction, epidemiological study, prevention, and effective vector control of CHIKV. For instance, a novel CHIKV strain found in new areas has the potential to lead to a new outbreak. Health authorities could plan and apply control strategies more effectively given the tools provided by this research.
\end{abstract}

Keywords: genetic characterization; Chikungunya virus; Aedes aegypti; Thailand 


\section{Introduction}

Chikungunya virus (CHIKV) is a species of the genus Alphavirus belonging to the family Togaviridae, which has a genome consisting of a linear, positive-sense, single-stranded RNA molecule of approximately $11.8 \mathrm{~kb}$. The genome of CHIKV is considered to be $5^{\prime}$ cap-nsP1-nsP2-nsP3-nsP4-(junction region)-C-E3-E2-6K-E1-poly (A) 3' [1,2]. CHIKV consists of three genotypes: East/Central/South African (ECSA), West African (WA), and Asian. Vazeille et al. (2007) revealed that the ECSA genotype carrying a new variant of mutation at alanine-to-valine (A226V) in the $E 1$ protein has spread in areas where Aedes albopictus (Skuse) is predominant. This mutation has shown to be increasing the fitness of the virus for Ae. albopictus mosquitoes as well as its infectivity [3].

CHIKV infection is one of the emerging and re-emerging mosquito-borne viral diseases transmitted by Aedes mosquitoes such as Ae. aegypti and Ae. albopictus, the Asian tiger mosquito associated with several recent large-scale epidemics $[4,5]$. CHIKV was initially transmitted through the vector Ae. aegypti, whereas Ae. albopictus showed a mutation in the E1-A226V of CHIKV for improving transmissibility to humans [6-8]. CHIKV infection has become a serious public health problem in many parts of the world. CHIKV was first identified in Tanzania in 1952 [9], and an outbreak occurred in a large tropical area (i.e., Africa, South Asia, and Southeast Asia) [10]. Moreover, cases of CHIKV from Europe, the USA, and Australia through travelers returning from affected areas were also recently reported [11,12]. In Thailand, the first reported case of CHIKV infection in Bangkok caused by the Asian genotype occurred in 1958 [13]. In 2008, a CHIKV epidemic was reported as the ECSA genotype [14-16].

CHIKV infection is characterized by high-grade fever, nausea, rash, and severe arthralgia. The symptoms are generally of short duration (i.e., approximately between 2-12 days), although some patients may have recurrent episodes for several weeks after infection [17-19]. CHIKV also involves systemic infection in many organ systems (e.g., renal, hepatic, cardiac, neurologic, and respiratory) [20]. There are no specific drugs or CHIKV-specific vaccines against the disease. Supportive treatment is mainly used to relieve the symptoms. CHIKV is increasing public health concerns due to its prevalence, geographical distribution, and severity; however, the options to help control these infections are still limited. Therefore, vector control is the principle strategy used to control CHIKV outbreaks.

The transovarial transmission in mosquitoes is one of mechanisms of CHIKV's maintenance in nature during adverse climatic conditions. During this period, the infected mosquito becomes inactive or unable to survive, and therefore the virus can establish a persistent infection within the mosquito. The virus disseminates to infect the ovary of the female mosquito and then infects the egg during oviposition [21]. Importantly, the eggs of Aedes mosquitoes are generally resistant to desiccation and are able to survive for a long period of time, leading to the persistence of CHIKV in their eggs. Therefore, the virus can persist through the larva stage and continue to the adult stage [22]. Moreover, previous studies reported that CHIKV transmission involves several Aedes species. For instance, Ae. aegypti has been identified as the main vector of CHIKV, and the transovarial transmission of the virus has been reported [23]. However, the number of mosquito generations through which the virus has successfully persisted has not been identified. Recently, it was found that CHIKV (Indian Ocean Lineage) isolated from Ae. albopictus in Southern Thailand could be transmitted vertically under laboratory conditions up to F5 and F6 generations of Ae. aegypti and Ae. albopictus, respectively [24].

Ae. albopictus has also been reported as a potential vector in Asia [5]. There are reports of vectors of CHIKV in Africa including Ae. africanus in East Africa; Ae. cordellieri and Ae. taylori in South Africa; and Ae. furcifer, Ae. dalzielii, Ae. luteocephalus, Ae. taylori, and Ae. vittatus in West Africa [25,26]. In Thailand, the Bureau of Epidemiology of Thailand Health Ministry reported 3794 of chikungunya cases in 27 provinces from 1 January-16 June 2019 [27]. However, the re-emergence of CHIKV outbreaks in Thailand is unpredictable, and effective disease control relies on vector mosquito control measures only. It is necessary to understand the transmission cycle of CHIKV associated with mosquito vectors in endemic areas. Therefore, in this study, we focused on the detection of CHIKV infection in both female and male Ae. aegypti around patients' homes in different regions of Thailand by using E1-nested 
RT-PCR. The data could be valuable for designing effective therapeutic strategies, vector control measures, and eradication of CHIKV associated with Ae. aegypti mosquitoes in Thailand.

\section{Results}

\subsection{Molecular Detection of CHIKV RNA in Ae. aegypti}

In this study, we developed new primers for the specific detection of the mutation at alanine-to-valine in the $E 1$ glycoprotein at position 226 (E1: A226V) in infected mosquitoes. The total samples used for CHIKV detection consisted of 900/1646 female and 746/1646 male Ae. aegypti mosquitoes, which were collected from the endemic area of CHIKV infection. Most samples were found around patients' homes from 27 provinces of 6 regions of Thailand (Figure 1). Our findings showed that CHIKV RNA were positive in $3.28 \%$ and $0.85 \%$ in female and male Ae. aegypti mosquitoes from Northern (Chiang Rai, Chiang Mai, and Nan), Northeastern (Nong Khai and Ubon Ratchathani), Central (Bangkok and Nakhon Sawan), and Southern (Songkhla, Prachuap Khiri Khan, and Krabi) regions, respectively, whereas $\mathrm{CHIKV}$ was not detected in Ae. aegypti samples from the Eastern region using E1-nested RT-PCR (Table 1).

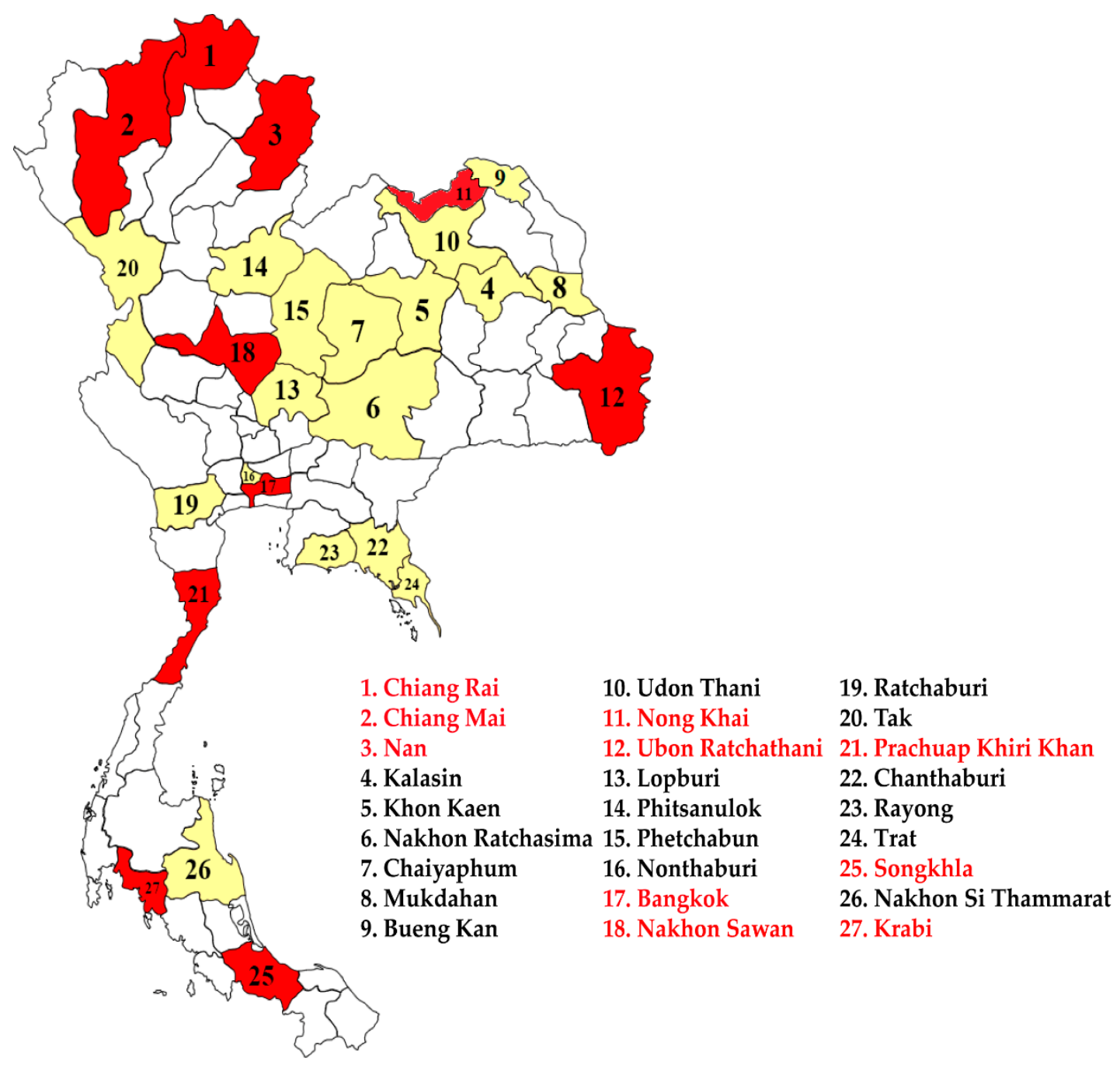

Figure 1. Map of Thailand showing locations of the sample collection sites in the 27 provinces of 6 regions in affected areas. Red indicates the collection locations of positive CHIKV in mosquito samples and yellow indicates negative CHIKV in mosquito samples. 
Table 1. Chikungunya virus (CHIKV) detection in Aedes aegypti collected from various regions of Thailand.

\begin{tabular}{|c|c|c|c|c|}
\hline \multirow{2}{*}{ Regions } & \multirow{2}{*}{ Provinces } & \multirow{2}{*}{ Total Sample (n) } & \multicolumn{2}{|c|}{ Chikungunya-Positive (n/total) } \\
\hline & & & Female & Male \\
\hline \multirow{3}{*}{ Northern } & Chiang Rai & 50 & $2 / 28$ & $0 / 22$ \\
\hline & Chiang Mai & 64 & $2 / 37$ & $0 / 27$ \\
\hline & Nan & 40 & $1 / 22$ & $0 / 18$ \\
\hline \multirow{9}{*}{ Northeastern } & Kalasin & 7 & $0 / 5$ & $0 / 2$ \\
\hline & Khon Kaen & 63 & $0 / 33$ & $0 / 30$ \\
\hline & Nakhon Ratchasima & 19 & $0 / 12$ & $0 / 7$ \\
\hline & Chaiyaphum & 40 & $0 / 25$ & $0 / 15$ \\
\hline & Mukdahan & 8 & $0 / 4$ & $0 / 4$ \\
\hline & Bueng Kan & 10 & $0 / 7$ & $0 / 3$ \\
\hline & Udon Thani & 60 & $0 / 32$ & $0 / 28$ \\
\hline & Nong Khai & 258 & $0 / 145$ & $3 / 113$ \\
\hline & Ubon Ratchathani & 75 & $10 / 42$ & $0 / 33$ \\
\hline \multirow{6}{*}{ Central } & Lopburi & 60 & $0 / 32$ & $0 / 28$ \\
\hline & Phitsanulok & 51 & $0 / 27$ & $0 / 24$ \\
\hline & Phetchabun & 51 & $0 / 32$ & $0 / 19$ \\
\hline & Nonthaburi & 21 & $0 / 13$ & $0 / 8$ \\
\hline & Bangkok & 89 & $11 / 51$ & $3 / 38$ \\
\hline & Nakhon Sawan & 64 & $2 / 35$ & $0 / 29$ \\
\hline \multirow{3}{*}{ Western } & Ratchaburi & 85 & $0 / 47$ & $0 / 38$ \\
\hline & Tak & 96 & $0 / 52$ & $0 / 44$ \\
\hline & Prachuap Khiri Khan & 93 & $24 / 46$ & $8 / 47$ \\
\hline \multirow{3}{*}{ Eastern } & Chanthaburi & 60 & $0 / 29$ & $0 / 31$ \\
\hline & Rayong & 45 & $0 / 22$ & $0 / 23$ \\
\hline & Trat & 60 & $0 / 29$ & $0 / 31$ \\
\hline \multirow{3}{*}{ Southern } & Songkhla & 80 & $1 / 38$ & $0 / 42$ \\
\hline & Nakhon Si Thammarat & 62 & $0 / 28$ & $0 / 34$ \\
\hline & Krabi & 35 & $1 / 27$ & $0 / 8$ \\
\hline & Total & 1646 & $54 / 900$ & $14 / 746$ \\
\hline
\end{tabular}

\subsection{Sequencing and Phylogenetic Analysis}

A total of 68 sequences of $E 1$-CHIKV from Ae. aegypti were obtained from five geographical regions of Thailand. Most of the sequences contained $539 \mathrm{bp}$. The BLAST results showed that the sequence was also similar to CHIKV isolated from the plasma and serum of patients in Malaysia (Accession no. KT324228) and India (Accession no. MK473628 and MK473637) with $>99 \%$ identity and a full 100\% coverage of the nucleotide sequences. The genetic variations of CHIKV from Ae. aegypti collected from different geographic regions showed a maximum of $4.3 \%$ between CHIKV-Ae. aegypti from Prachuap Khiri Khan and Nan provinces. The intraspecific variation analysis in each province showed $0-1.9 \%$ variation. Interestingly, we found 17 (1.03\%) of CHIKV from female of Ae. aegypti collected from Ubon Ratchathani (10 samples); 6 samples from Chiang Rai, Chiang Mai, and Nakhon Sawan (two samples from each province); and 1 sample from Songkhla province. All sequences from this outbreak revealed that the E1: A226V mutation was similar to the sequences isolated from the serum of patients in the previous outbreak from Thailand, Malaysia, Korea, Singapore, India, and Sri Lanka during 2008-2010. Additionally, the substitution of lysine by glutamic acid at position 211 (E1: K211E) was observed in all 50 samples collected from Nong Khai (3 samples), Bangkok (14 samples), Prachuap Khiri Khan (32 samples), and Krabi (1 sample). The sequences of E1: K211E were similar to CHIKV isolated from the outbreak in Bangladesh, Pakistan, India, Hong Kong, Australia, and Italy during 2016-2017 and in Thailand 2018 (Figure 2, Figure S1). The phylogenetic tree indicates that the CHIKV in Ae. aegypti samples could be clearly classified into two clades consisting of Indian Ocean Clade and East/South African Clade. Both clades belong to the ECSA genotype. One sample of CHIKV in Ae. aegypti from 
Nan province was of the East/South African Clade (Figure 3). All sequences of CHIKV in Ae. aegypti were submitted to the GenBank database under accession numbers MN114279-MN114346.

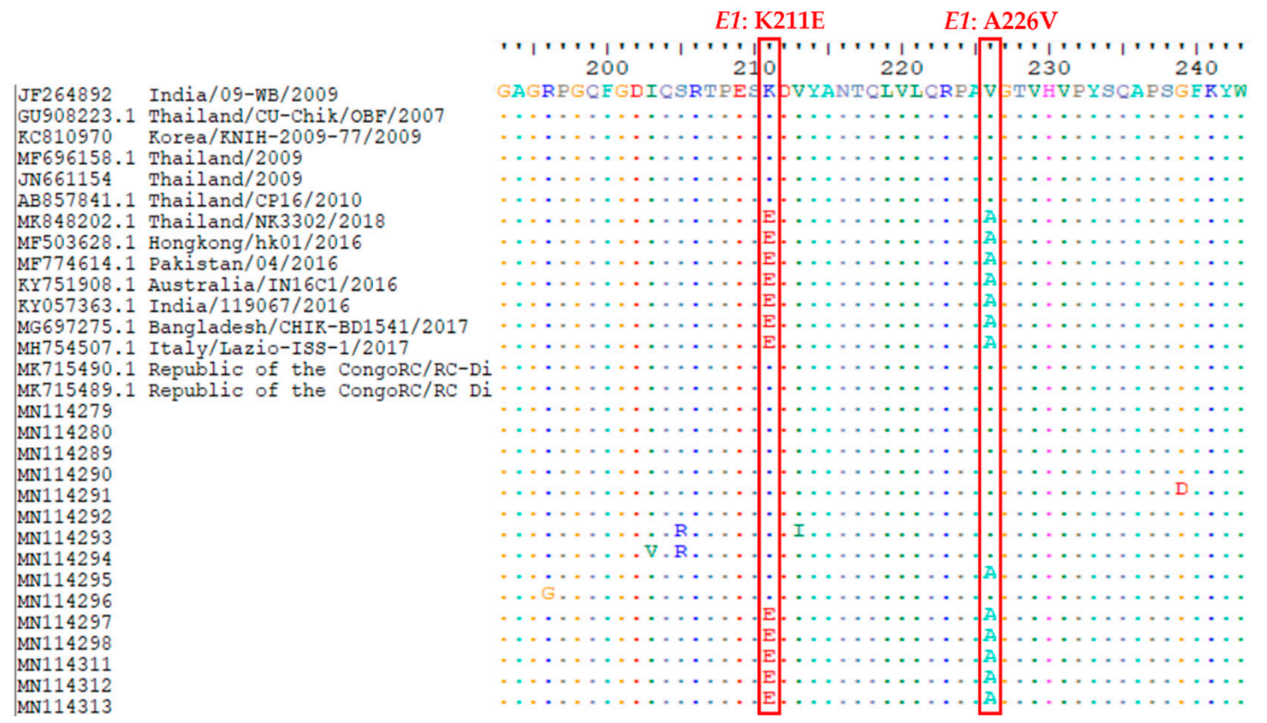

Figure 2. Showing a portion of the alignment of amino acid sequences of the $E 1$ gene of CHIKV in Ae. aegypti at positions of the $\mathrm{A} 226 \mathrm{~V}$ and $\mathrm{K} 211 \mathrm{E}$ mutations, indicated by red vertical columns.
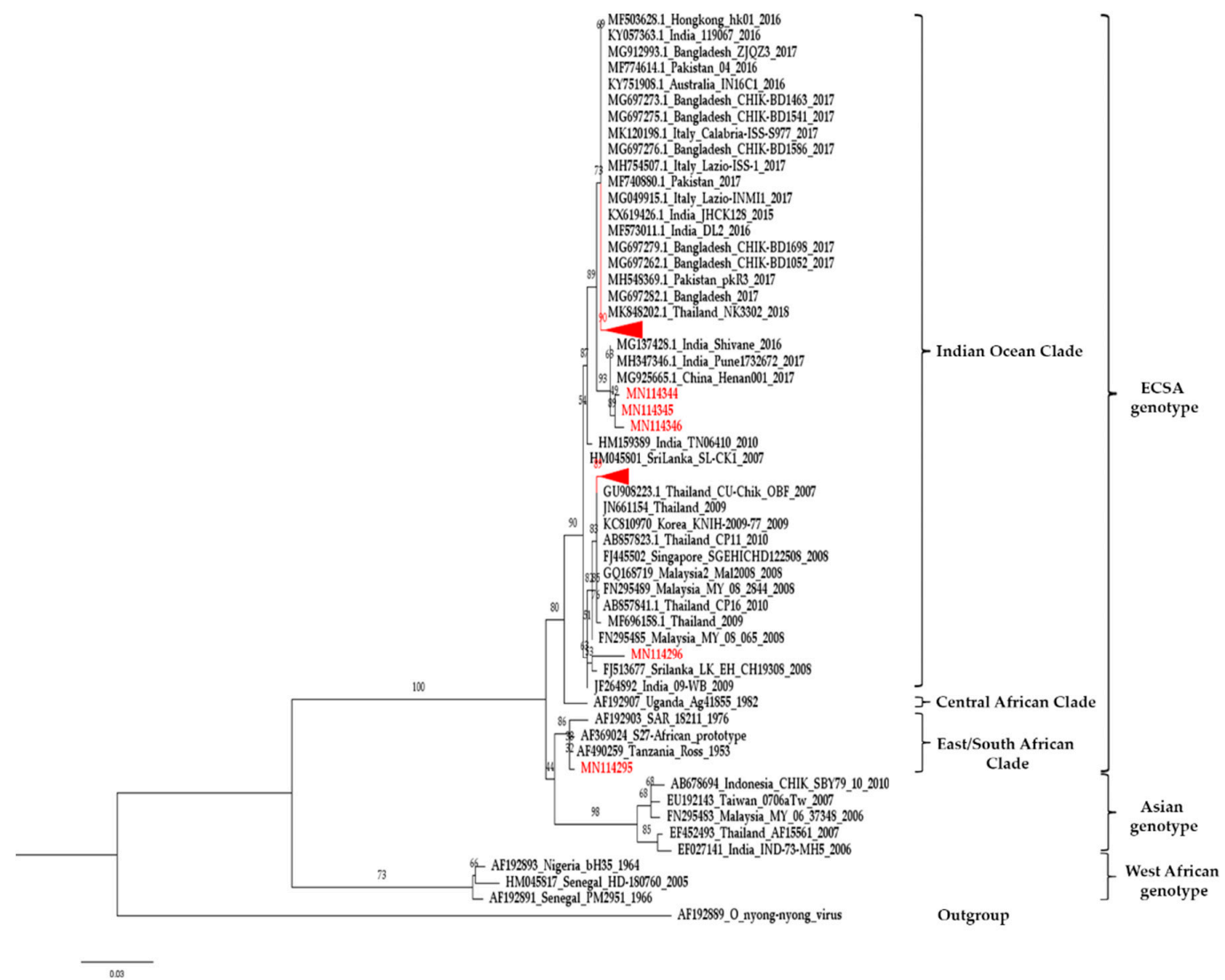

Figure 3. Phylogenetic tree of CHIKV in mosquitoes constructed from partial E1 sequences from all regions of Thailand. The maximum likelihood was constructed with IQ-TREE by using the maximum-likelihood method with 1000 ultrafast bootstrap replicates. The best-fit model of substitution was found using the auto function on the IQ-TREE web server. The sequences from this study are indicated with a red color. Code of MN114344, MN114345, and MN114346 is CHIKV-Ae. aegypti from Nong Khai, and MN114296 and MN114295 are CHIKV-Ae. aegypti from Songkhla and Nan, respectively. 


\section{Discussion}

Chikungunya fever is an emerging arbovirus infection, representing a silent worldwide health problem. In Thailand, the previous outbreak of CHIKV in 1958 was of the Asian genotype [13]. However, the CHIKV outbreak in late 2008 was of the ECSA genotype [14-16], which was 99-100\% closely related to CHIKV from the outbreaks in India in 2007 [28] and Singapore in 2008 [29]. In Thailand during 2008-2009, the large outbreak of CHIKV (ECSA genotype) in the southern provinces also rapidly spread across Thailand, with more than 50,000 infected cases with the E1: A226V mutation [30]. In 2013, Wanlapakorn et al. reported an outbreak of CHIKV infection in the northeastern region, Bueng Kan province, and suggested that these isolations in the Indian Ocean clade contained the E1: A226V mutation and were grouped into the ECSA genotype. This evidence revealed the presence and continued circulation of the E1: A226V mutation in the Indian Ocean clade of CHIKV in Thailand since 2008 [31]. Recently, the re-emergence of CHIKV was reported by the Bureau of Epidemiology of Thailand Health Ministry, as mentioned previously [27]. However, little information is available about the molecular epidemiology of CHIKV transmitted from the mosquitoes, Ae. Aegypti, in Thailand. In the present study, we focused on the genetic divergence of sequence data of CHIKV from both female and male Ae. aegypti collected from endemic areas of Thailand. The results showed that CHIKV RNA was detected in female Ae. aegypti (3.28\%) more than male Ae. aegypti (0.85\%). A previous report showed the infection rate of CHIKV in both female and male pools of Ae. aegypti (8.5\%) and Ae. albopictus (7.6\%) collected from the southern part of Thailand [5]. Additionally, CHIKV RNA were only detected in $6.4 \%$ of Ae. aegypti (3.8\% females and $2.6 \%$ larvae) from Eastern Thailand [32]. In Vietnam, CHIKV-positive individual female Ae. aegypti were detected in two $(0.18 \%)$ samples from Dac Nong and Long An [33]. In the literature, it is suggested that Ae. aegypti might be a vector of CHIKV and also could support the vertical transmission of CHIKV in Ae. aegypti. Several reports detected transovarial transmission of ECSA genotype CHIKV under natural conditions in field-caught Ae. aegypti and Ae. albopictus in different parts of the world [34-36]; moreover, under laboratory conditions, the transovarial transmission has also been demonstrated in both Ae. aegypti and Ae. albopictus [23,24]. Honório et al. (2019) has recently suggested the first vertical transmission of Asian genotype CHIKV in Brazilian and Florida populations of Ae. albopictus in the laboratory [37]. However, in this study, we only collected Ae. aegypti because we wanted to focus on studying inside patients' houses, in which Ae. aegypti are commonly found. These mosquitoes usually rest inside the houses after feeding on human blood. Therefore, complete studies on Ae. albopictus and CHIKV in Thailand should be done in the future.

It is possible to demonstrate the co-circulation of both Asian and ECSA genotypes in Thailand. Therefore, the present study demonstrates the genetic diversity of CHIKV in field-caught Ae. aegypti mosquitoes collected from endemic areas of Thailand. Our results show that 17 samples found the E1: A226V mutation from female of Ae. aegypti; moreover, we found that the E1: K211E mutation was observed in 50 samples from both female and male Ae. aegypti collected from Nong Khai, Bangkok, Prachuap Khiri Khan, and Krabi. For phylogenetic analyses, molecular evolution analyses of E1 indicated that all positive CHIKV samples were classified into Indian Ocean and East/South African clades. Both clades were present in the ECSA genotype. We assumed that the widespread and renewed chikungunya fever epidemic in the current outbreak in Thailand may contribute to the molecular evolutionary adaptation acquired by CHIKV as a result of the A226V and K211E mutations in the $E 1$ gene in Ae. aegypti in the different regions of Thailand. In the past, a major epidemic of CHIKV started in many Indian Ocean island nations in early 2005 [38]. In 2007, the implications of A226V mutation have been increased severity, reported mortality, and a large epidemic in Kerala State, India; additionally, Ae. albopictus was a potential vector for CHIKV during these outbreaks [39]. Tsetsarkin et al. (2007) revealed that the E1: A226V mutation enhances the ability of the salivary gland of Ae. albopictus to become infected with a virus, and therefore, increases the capability of the mosquitoes to transmit the virus to another host ; in contrast, the E1: A226V mutation has a slightly negative effect on CHIKV infectivity, a negligible effect on dissemination, and a slight positive 
effect on the transmissibility of CHIKV by Ae. aegypti [40]. However, our results showed that all 17 sequences representative from this outbreak revealed E1: A226V, as observed in 2008-2010 isolates from the serum of Thai patients as Accession nos. MF696158, AB857823, AB857841, and JN661154, respectively [41]. The appearance and continued circulation of the E1: A226V mutation in Thailand has been suspected since 2008. Interestingly, we found the E1: K211E mutation in 50 samples of Ae. aegypti, which were reported in Bangladesh, Pakistan, India, Hong Kong, Australia, and Italy during 2016-2017 [42]. This evidence supports that CHIKV may have been distributing and evolving in different geographic regions of the world and may have been depending on the prevalence of the vectors and their efficiency in transmitting of CHIKV. Moreover, it might possibly occur through the migration, travel, or residence of people in high-risk areas of CHIKV infection. There is one report showing that E1: K211E mutation was detected earlier in the Asian lineage [43], and has been found in the ECSA lineage in one sample from Andhra Pradesh, India [44]. The E1: K211E variations have also been invested in the autochthonous imported case in Southeastern France from India in 2010 [45]. Agarwal et al. (2016) showed that the CHIKV in Ae. aegypti demonstrated that the E1: K211E mutation led to increased infectivity, dissemination, and transmission, whereas the aforementioned mutation was not observed in Ae. albopictus [46]. It is interesting to point out that the mutants of E1: A226V and E1: K211E have been found in both humans and other mosquitoes in Thailand. If these mutated strains occur in a new setting, major CHIKV outbreaks can be predicted.

\section{Materials and Methods}

\subsection{Ethics Statement}

The study was approved by the animal research ethics committee of Chulalongkorn University Animal Care and Use Protocol (CU-ACUP), Faculty of Medicine, Chulalongkorn University, Bangkok, Thailand (COA No. 023/2560).

\subsection{Sample Collection}

A total of 1646 adult mosquitoes were collected in and around the house of confirmed CHIKV-infected patients using mosquito aspirators. The larvae were also collected using a plastic dropper or plastic cup. The collections were conducted in different geographical regions of Thailand, including the Northern (Chiang Rai, Chiang Mai, and Nan), Northeastern (Kalasin, Khon Kaen, Nakhon Ratchasima, Chaiyaphum, Mukdahan, Bueng Kan, Udon Thani, Nong Khai, and Ubon Ratchathani), Central (Lop Buri, Phitsanulok, Phetchabun, Nonthaburi, Bangkok, and Nakhon Sawan), Eastern (Chanthaburi, Rayong, and Trat), Western (Ratchaburi, Tak, and Prachuap Khiri Khan), and Southern (Songkhla, Nakhon Si Thammarat, and Krabi) regions. The mosquito samples were kept in liquid nitrogen and transferred to the laboratory of Vector Biology and Vector-Borne Disease Research Unit, Department of Parasitology, Faculty of Medicine, Chulalongkorn University. Based on their morphological characteristics, all samples were differentiated according to their sex and species. Additionally, the larvae were reared into adult mosquitoes for species identification and then individual mosquitoes were tested for the viral detection.

\subsection{Viral RNA Extraction}

Viral RNA was extracted from individual mosquitoes as follows. First, the mosquito was ground in 1X phosphate-buffered saline (PBS) and centrifuged at $11,000 \times g$ for $5 \mathrm{~min}$. The supernatant was processed for viral RNA extraction using a viral RNA extraction kit, Invisorb ${ }^{\circledR}$ Spin Virus RNA Mini kit (STRATEC Molecular GmbH, Berlin, Germany), according to the manufacturer's instructions. The RNA concentration was quantified by a Nano Drop 2000c spectrophotometer (Thermo Fisher Scientific, MA, USA). The extracted RNA samples were used immediately for CHIKV detection, and the samples were maintained for long-term storage at $-80^{\circ} \mathrm{C}$. 


\subsection{CHIKV RNA Detection}

The RNA extracted from individual mosquitoes were amplified and tested for CHIKV detection using nested RT-PCR. The first amplification was performed using the two outer primer pairs, targeting the $E 1$ gene of CHIKV (E1-10145 F: 5'-ACAAAACCGTCATCCCGTCTC-3' genome position 10145-10165 and E1-11158R: 5'-TGACTATGTGGTCCTTCGGAGG-3' genome position 11137-11158) [47]. The primers used for the second amplification were newly designed based on the E1 gene sequences, as forward primer 5'-GCGCCTACTGCTTCTGCGA-3' and reverse primer sequences were $5^{\prime}$-CTTCATCGCTC TTACCGGGT- $3^{\prime}$. The first round of PCR reaction was carried out in a final volume of $25 \mu \mathrm{L}$ using the Superscript III one-step RT-PCR kit (Invitrogen, Grand Island, NY, USA), which consisted of $12.5 \mu \mathrm{L}$ of 2 XR reaction mix, $0.7 \mu \mathrm{L}(10 \mu \mathrm{M})$ of each primer, $1 \mu \mathrm{L}$ of Taq polymerase, $4.1 \mu \mathrm{L}$ of sterile nuclease-free water, and $6.0 \mu \mathrm{L}$ of RNA template. The PCR cycling conditions were performed with an initial incubation at $50^{\circ} \mathrm{C}$ for $30 \mathrm{~min}$, denaturation at $95^{\circ} \mathrm{C}$ for $15 \mathrm{~min}$, and followed by 40 cycles of $95^{\circ} \mathrm{C}$ for $1 \mathrm{~min}, 64^{\circ} \mathrm{C}$ for $1 \mathrm{~min}, 72{ }^{\circ} \mathrm{C}$ for $1 \mathrm{~min}$, and the final extension at $72{ }^{\circ} \mathrm{C}$ for $10 \mathrm{~min}$. Two microliters from the first amplification were further amplified with the inner pairs of the primer in a final volume of $25 \mu \mathrm{L}$, containing $2.5 \mu \mathrm{L}$ of $10 X$ buffer, $2.5 \mu \mathrm{L}(25 \mathrm{mM})$ of $\mathrm{MgCl}_{2}, 2.5 \mu \mathrm{L}$ $(10 \mu \mathrm{M})$ of dNTP (GeneAll, Seoul, Korea), $0.4 \mu \mathrm{L}(10 \mu \mathrm{M})$ of each inner primer, $0.2 \mu \mathrm{L}(5 \mathrm{U} / \mu \mathrm{L})$ of Taq polymerase (Thermo Fisher Scientific, Waltham, MA, USA), and $14.5 \mu \mathrm{L}$ of sterile nuclease-free water. The reaction mixture was amplified using the following parameters: $95^{\circ} \mathrm{C}$ for $3 \mathrm{~min}$, followed by 40 cycles of $95{ }^{\circ} \mathrm{C}$ for $30 \mathrm{~s}, 62{ }^{\circ} \mathrm{C}$ for $30 \mathrm{~s}, 72{ }^{\circ} \mathrm{C}$ for $1 \mathrm{~min}$, and the final step at $72{ }^{\circ} \mathrm{C}$ for $7 \mathrm{~min}$. The amplified products were analyzed on a $1.5 \%$ agarose gel, stained with ethidium bromide, and then visualized under ultraviolet light with Quantity One Quantification Analysis Software version 4.5.2 (Gel DocEQ System; Bio-Rad, Hercules, CA, USA).

\subsection{DNA Cloning and Sequencing}

The positive PCR amplicons were directly ligated to pGEM-T Easy Vector (Promega, Madison, WI, USA), using T4 DNA ligase, following the manufacturer's recommendations. The resulting constructs were transformed into competent bacterial cells (Escherichia coli DH5 $\alpha$ strain) and then the bacterial transformants were screened using the blue-white colony system. The colonies suspected of carrying the DNA fragment were cultured, and the plasmid DNA was isolated using the Invisorb ${ }^{\circledR}$ Spin Plasmid Mini Kit (STRATEC molecular GmbH, Berlin, Germany), according to the manufacturer's instructions. The purified plasmids were sent to a commercial company (Macrogen, Seoul, Korea) for direct DNA sequencing.

\subsection{Phylogenetic Tree Construction}

The nucleotide sequences were aligned using the BioEdit Sequence Alignment Editor Version 7.2.5. The phylogenetic trees were constructed using the maximum-likelihood method with IQ-TREE on the IQ-TREE web server (http://iqtree.cibiv.univie.ac.at/) assessed by the ultrafast bootstrap with 1000 replicates. The best-fit model of substitution was found using the auto function on the IQ-TREE web server. Eventually, the phylogenetic tree was visualized and edited using FigTree v.1.4.4 software.

\section{Conclusions}

In this study, we highlight the natural infection of CHIKV RNA in female and male Ae. aegypti from the chikungunya fever endemic area of Thailand. Moreover, CHIKV-positive samples demonstrated the presence of vertical transmission in the field population of Ae. aegypti. The genetic characteristics of CHIKV based on the E1 sequences showed the ECSA genotype and the mutation of virus containing E1: A226V and E1: K211E, which were associated with increased infectivity, dissemination, and transmission in the Ae. aegypti vector. Widespread surveys throughout the country covering a large area and geographic distribution should be performed for a better understanding of the epidemiology of CHIKV through virus and vertical transmission. The data of molecular evidence provide the basis for studying 
the epidemiology, prevention, and effective control for CHIKV vector, as well as the chikungunya fever outbreak prediction in Thailand.

Supplementary Materials: The following are available online at http://www.mdpi.com/2076-0817/8/3/121/s1, Figure S1: Showing full of alignment of amino acid sequences of the E1 gene of CHIKV in Ae. aegypti at positions of the A226V and K211E mutations.

Author Contributions: Conceptualization, P.I., A.P., and P.S.; methodology, P.I.; software, P.I. and A.P.; validation, P.I., P.S. and A.P.; formal analysis, P.S.; investigation, R.B. (Rungfar Boonserm) and S.S.-S.; resources, R.B. (Rome Buathong), S.W. and Y.P.; data curation, P.S. and P.I.; writing —original draft preparation, P.I. and A.P.; writing-review and editing, P.S., A.P. and N.B.; visualization, Y.P. and P.S.; supervision, P.S.; project administration, P.I.; funding acquisition, P.S.

Funding: This study was supported by the National Research Council of Thailand and Health Systems Research Institute (Grant No. 61-003), Thailand Research Fund through the Royal Golden Jubilee Ph.D. program (PHD/0054/2560), National Science and Technology Development Agency (Thailand) (Grant No. P-16-50702), and the World Health Organization Thailand (WHO-Thailand) and the United States Agency for International Development (USAID) grant.

Acknowledgments: We would like to thank the staff of Vector Biology and Vector Borne Disease Research Unit, Department of Parasitology, Faculty of Medicine, Chulalongkorn University and the Staff of National Institute of Health, Department of Medical Sciences and Department of Disease Control, Bureau of Epidemiology, Ministry of Public Health, Thailand.

Conflicts of Interest: The authors declare no conflict of interest.

\section{References}

1. Chhabra, M.; Mittal, V.; Bhattacharya, D.; Rana, U.; Lal, S. Chikungunya fever: A re-emerging viral infection. Indian J. Med. Microbiol. 2008, 26, 5-12. [CrossRef] [PubMed]

2. Ganesan, V.K.; Duan, B.; Reid, S.P. Chikungunya Virus: Pathophysiology, Mechanism, and Modeling. Viruses 2017, 9, 368. [CrossRef]

3. Vazeille, M.; Moutailler, S.; Coudrier, D.; Rousseaux, C.; Khun, H.; Huerre, M.; Thiria, J.; Dehecq, J.; Fontenille, D.; Schuffenecker, I.; et al. Two Chikungunya isolates from the outbreak of La Reunion (Indian Ocean) exhibit different patterns of infection in the mosquito, Aedes albopictus. PLoS ONE 2007, 2, e1168. [CrossRef] [PubMed]

4. Sudeep, A.B.; Parashar, D. Chikungunya: An overview. J. Biosci. 2008, 33, 443-449. [CrossRef] [PubMed]

5. Thavara, U.; Tawatsin, A.; Pengsakul, T.; Bhakdeenuan, P.; Chanama, S.; Anantapreecha, S.; Molito, C.; Chompoosri, J.; Thammapalo, S.; Sawanpanyalert, P.; et al. Outbreak of chikungunya fever in Thailand and virus detection in field population of vector mosquitoes, Aedes aegypti (L.) and Aedes albopictus skuse (Diptera: Culicidae). Southeast Asian J. Trop. Med. Public Health 2009, 40, 951-962. [PubMed]

6. Enserink, M. Infectious diseases. Massive outbreak draws fresh attention to little-known virus. Science 2006, 311, 1085. [CrossRef] [PubMed]

7. Reiter, P.; Fontenille, D.; Paupy, C. Aedes albopictus as an epidemic vector of chikungunya virus: Another emerging problem? Lancet Infect. Dis. 2006, 6, 463-464. [CrossRef]

8. Schuffenecker, I.; Iteman, I.; Michault, A.; Murri, S.; Frangeul, L.; Vaney, M.C.; Lavenir, R.; Pardigon, N.; Reynes, J.M.; Pettinelli, F.; et al. Genome microevolution of chikungunya viruses causing the Indian Ocean outbreak. PLoS Med. 2006, 3, e263. [CrossRef]

9. Ross, R.W. The Newala epidemic III; the virus: Isolation, pathogenic properties and relationship to the epidemic. J. Hyg. 1956, 54, 177-191. [CrossRef]

10. Griffin, D.E. Alphaviruses. In Fields Virology; Knipe, D.M., Howley, R.M., Eds.; Lippincott, Williams \& Wilkins: Philadelphia, PA, USA, 2001; pp. 917-962.

11. Centers for Disease Control and Prevention (CDC). Chikungunya fever diagnosed among international travelers United States, 2005-2006. MMWR Morb. Mortal. Wkly. Rep. 2006, 55, 1040-1042.

12. Bonilauri, P.; Bellini, R.; Calzolari, M.; Angelini, R.; Venturi, L.; Fallacara, F.; Cordioli, P.; Angelini, P.; Venturelli, C.; Merialdi, G.; et al. Chikungunya virus in Aedes albopictus, Italy. Emerg. Infect. Dis. 2008, 14, 852-854. [CrossRef] [PubMed]

13. Aikat, B.K.; Konar, N.R.; Banerjee, G. Hemorrhagic fever in Calcutta area. Indian J. Med. Res. 1964, 52, 660-675. [PubMed] 
14. Thaikruea, L.; Thammapalo, S.; Prikchoo, P.; Binnisoh, R.; Klangvang, N. Epidemic of New Chikungunya Viral Genotype and Clinical Manifestations in Thailand, 2008-2009. Chiang Mai Med. J. 2011, 50, 1-11.

15. Theamboonlers, A.; Rianthavorn, P.; Praianantathavorn, K.; Wuttirattanakowit, N.; Poovorawan, Y. Clinical and molecular characterization of chikungunya virus in South Thailand. Jpn. J. Infect. Dis. 2009, 62, 303-305. [PubMed]

16. Rianthavorn, P.; Prianantathavorn, K.; Wuttirattanakowit, N.; Theamboonlers, A.; Poovorawan, Y. An outbreak of chikungunya in southern Thailand from 2008 to 2009 caused by African strains with A226V mutation. Int. J. Infect. Dis. 2010, 14, e161-e165. [CrossRef] [PubMed]

17. Powers, A.M.; Logue, C.H. Changing patterns of chikungunya virus: Re-emergence of a zoonotic arbovirus. J. Gen. Virol. 2007, 88, 2363-2377. [CrossRef] [PubMed]

18. Robinson, M.C. An epidemic of virus disease in Southern Province, Tanganyika Territory, in 1952-53. I. Clinical features. Trans. R. Soc. Trop. Med. Hyg. 1955, 49, 28-32. [CrossRef]

19. Pialoux, G.; Gaüzère, B.A.; Jauréguiberry, S.; Strobel, M. Chikungunya, an epidemic arbovirosis. Lancet Infect. Dis. 2007, 7, 319-327. [CrossRef]

20. Tandale, B.V.; Sathe, P.S.; Arankalle, V.A.; Wadia, R.S.; Kulkarni, R.; Shah, S.V.; Shah, S.K.; Sheth, J.K.; Sudeep, A.B.; Tripathy, A.S.; et al. Systemic involvements and fatalities during Chikungunya epidemic in India, 2006. J. Clin. Virol. 2009, 46, 145-149. [CrossRef]

21. Hardy, J.L.; Houk, E.J.; Kramer, L.D.; Reeves, W.C. Intrinsic factors affecting vector competence of mosquitoes for Arboviruses. Annu. Rev. Entomol. 1983, 28, 229-262. [CrossRef]

22. Miller, B.R.; Nasci, R.S.; Godsey, M.S.; Savage, H.M.; Lutwama, J.J.; Lanciotti, R.S.; Peters, C.J. First field evidence for natural vertical transmission of West Nile virus in Culex univittatus complex mosquitoes from Rift Valley Province, Kenya. Am. J. Trop. Med. Hyg. 2000, 62, 240-246. [CrossRef] [PubMed]

23. Agarwal, A.; Dash, P.K.; Singh, A.K.; Sharma, S.; Gopalan, N.; Rao, P.V.; Parida, M.M.; Reiter, P. Evidence of experimental vertical transmission of emerging novel ECSA genotype of chikungunya virus in Aedes aegypti. PLoS Negl. Trop. Dis. 2014, 8, e2990. [CrossRef] [PubMed]

24. Chompoosri, J.; Thavara, U.; Tawatsin, A.; Boonserm, R.; Phumee, A.; Sangkitporn, S.; Siriyasatien, P. Vertical transmission of Indian Ocean Lineage of chikungunya virus in Aedes aegypti and Aedes albopictus mosquitoes. Parasit. Vectors 2016, 9, 227. [CrossRef] [PubMed]

25. Powers, A.M.; Brault, A.C.; Tesh, R.B.; Weaver, S.C. Re-emergence of chikungunya and o'nyong-nyong viruses: Evidence for distinct geographical lineages and distant evolutionary relationships. J. Gen. Virol. 2000, 81, 471-479. [CrossRef] [PubMed]

26. Diallo, M.; Thonnon, J.; Traore-Lamizana, M.; Fontenille, D. Vectors of chikungunya virus in Senegal: Current data and transmission cycles. Am. J. Trop. Med. Hyg. 1999, 60, 281-286. [CrossRef]

27. Bureau of Epidemiology, Department of Disease Control, MoPH, Thailand. Chikungunya. Available online: http://www.boe.moph.go.th/boedb/surdata/disease.php?ds=84 (accessed on 20 June 2019).

28. Kumar, N.P.; Joseph, R.; Kamaraj, T.; Jambulingam, P. A226V mutation in virus during the 2007 chikungunya outbreak in Kerala, India. J. Gen. Virol. 2008, 89, 1945-1948. [CrossRef] [PubMed]

29. Ng, K.W.; Chow, A.; Win, M.K.; Dimatatac, F.; Neo, H.Y.; Lye, D.C.; Leo, Y.S. Clinical features and epidemiology of chikungunya infection in Singapore. Singapore Med. J. 2009, 50, 785-790.

30. Suangto, P.; Uppapong, T.; Chikungunya fever. Annual Epidemiological Surveillance Report 2009, Bureau of Epidemiology, Department of Disease Control, Ministry of Public Health. Available online: http://www.boe. moph.go.th/Annual/Annual\%202552/Main.htm (accessed on 22 June 2019).

31. Wanlapakorn, N.; Thongmee, T.; Linsuwanon, P.; Chattakul, P.; Vongpunsawad, S.; Payungporn, S.; Poovorawan, Y. Chikungunya outbreak in Bueng Kan Province, Thailand, 2013. Emerg. Infect. Dis. 2014, 20, 1404-1406. [CrossRef]

32. Tawatsin, A.; Phumee, A.; Thavara, U.; Sirisopa, P.; Ritthison, W.; Thammakosol, K.; Intayot, P.; Joyjinda, Y.; Wacharapluesadee, S.; Hemachudha, T.; et al. High infection rate of Zika virus in mosquitoes collected from an area of active Zika virus transmission in eastern Thailand. Thai. J. Vet. Med. 2019, 48, 551-558.

33. Pham Thi, K.L.; Briant, L.; Gavotte, L.; Labbe, P.; Perriat-Sanguinet, M.; Cornillot, E.; Vu, T.D.; Nguyen, T.Y.; Tran, V.P.; Nguyen, V.S.; et al. Incidence of dengue and chikungunya viruses in mosquitoes and human patients in border provinces of Vietnam. Parasit. Vectors 2017, 10, 556. [CrossRef] 
34. Delatte, H.; Paupy, C.; Dehecq, J.S.; Thiria, J.; Failloux, A.B.; Fontenille, D. Aedes albopictus, vector of chikungunya and dengue viruses in Reunion Island: Biology and control. Parasite 2008, 15, 3-13. [CrossRef] [PubMed]

35. Ratsitorahina, M.; Harisoa, J.; Ratovonjato, J.; Biacabe, S.; Reynes, J.M.; Zeller, H.; Raoelina, Y.; Talarmin, A.; Richard, V.; Soares, J.L. Outbreak of dengue and Chikungunya fevers, Toamasina, Madagascar, 2006. Emerg. Infect. Dis. 2008, 14, 1135-1137. [CrossRef] [PubMed]

36. Hailin, Z.; Yunzhi, Z.; Zhuqing, M. Transovarial transmission of Chikungunya virus in Aedes albopictus and Aedes aegypti mosquitoes. Chin. J. Virol. 1993, 9, 222-227.

37. Honório, N.A.; Wiggins, K.; Eastmond, B.; Câmara, D.; Alto, B.W. Experimental Vertical Transmission of Chikungunya Virus by Brazilian and Florida Aedes Albopictus Populations. Viruses 2019, 11, 353. [CrossRef] [PubMed]

38. Dash, P.K.; Parida, M.M.; Santhosh, S.R.; Verma, S.K.; Tripathi, N.K.; Ambuj, S.; Saxena, P.; Gupta, N.; Chaudhary, M.; Babu, J.P.; et al. East Central South African genotype as the causative agent in reemergence of Chikungunya outbreak in India. Vector. Borne Zoonotic Dis. 2007, 7, 519-527. [CrossRef] [PubMed]

39. Santhosh, S.R.; Dash, P.K.; Parida, M.M.; Khan, M.; Tiwari, M.; Lakshmana Rao, P.V. Comparative full genome analysis revealed E1: A226V shift in 2007 Indian Chikungunya virus isolates. Virus. Res. 2008, 135, 36-41. [CrossRef] [PubMed]

40. Tsetsarkin, K.A.; Vanlandingham, D.L.; McGee, C.E.; Higgs, S. A single mutation in chikungunya virus affects vector specificity and epidemic potential. PLoS Pathog. 2007, 3, e201. [CrossRef]

41. Tuekprakhon, A.; Nakayama, E.E.; Bartholomeeusen, K.; Puiprom, O.; Sasaki, T.; Huits, R.; Luplertlop, N.; Kosoltanapiwat, N.; Maneekan, P.; Ariën, K.K.; et al. Variation at position 350 in the Chikungunya virus 6K-E1 protein determines the sensitivity of detection in a rapid E1-antigen test. Sci. Rep. 2018, 8, 1094. [CrossRef]

42. Melan, A.; Aung, M.S.; Khanam, F.; Paul, S.K.; Riaz, B.K.; Tahmina, S.; Kabir, M.I.; Hossain, M.A.; Kobayashi, N. Molecular characterization of chikungunya virus causing the 2017 outbreak in Dhaka, Bangladesh. New Microbes New Infect. 2018, 24, 14-16. [CrossRef]

43. Arankalle, V.A.; Shrivastava, S.; Cherian, S.; Gunjikar, R.S.; Walimbe, A.M.; Jadhav, S.M.; Sudeep, A.B.; Mishra, A.C. Genetic divergence of Chikungunya viruses in India (1963-2006) with special reference to the 2005-2006 explosive epidemic. J. Gen. Virol. 2007, 88, 1967-1976. [CrossRef]

44. Kumar, C.V.M.N.; Johnson, A.M.A.; Gopal, D.V.R.S. Molecular characterization of chikungunya virus from Andhra Pradesh, India \& phylogenetic relationship with Central African isolates. Ind. J. Med. Res. 2007, 126, 534-540.

45. Grandadam, M.; Caro, V.; Plumet, S.; Thiberge, J.M.; Souarès, Y.; Failloux, A.B.; Tolou, H.J.; Budelot, M.; Cosserat, D.; Leparc-Goffart, I.; et al. Chikungunya virus, Southeastern France. Emerg. Infect. Dis. 2011, 17, 910-913. [CrossRef] [PubMed]

46. Agarwal, A.; Sharma, A.K.; Sukumaran, D.; Parida, M.; Dash, P.K. Two novel epistatic mutations (E1:K211E and E2:V264A) in structural proteins of Chikungunya virus enhance fitness in Aedes aegypti. Virology 2016, 497, 59-68. [CrossRef] [PubMed]

47. Santhosh, S.R.; Dash, P.K.; Parida, M.; Khan, M.; Rao, P.V. Appearance of E1: A226Vmutant Chikungunya virus in Coastal Karnataka, India during 2008 outbreak. Virol. J. 2009, 6, 172. [CrossRef] [PubMed]

(C) 2019 by the authors. Licensee MDPI, Basel, Switzerland. This article is an open access article distributed under the terms and conditions of the Creative Commons Attribution (CC BY) license (http://creativecommons.org/licenses/by/4.0/). 